\title{
A Study on Ultrasonic Elliptical Vibration Cutting of Inconel 718
}

\author{
Zhao Haidong, Zou Ping, Ma Wenbin, and Zhou Zhongming \\ School of Mechanical Engineering and Automation, Northeastern University, Shenyang 110819, China \\ Correspondence should be addressed to Zou Ping; pzou425@163.com
}

Received 16 March 2016; Revised 30 May 2016; Accepted 9 June 2016

Academic Editor: Salvatore Strano

Copyright (C) 2016 Zhao Haidong et al. This is an open access article distributed under the Creative Commons Attribution License, which permits unrestricted use, distribution, and reproduction in any medium, provided the original work is properly cited.

\begin{abstract}
Inconel 718 is a kind of nickel-based alloys that are widely used in the aerospace and nuclear industry owing to their high temperature mechanical properties. Cutting of Inconel 718 in conventional cutting (CC) is a big challenge in modern industry. Few researches have been studied on cutting of Inconel 718 using single point diamond tool applying the UEVC method. This paper shows an experimental study on UEVC of Inconel 718 by using polycrystalline diamond (PCD) coated tools. Firstly, cutting tests have been carried out to study the effect of machining parameters in the UEVC in terms of surface finish and flank wear during machining of Inconel 718. The tests have clearly shown that the PCD coated tools in cutting of Inconel 718 by the UEVC have better performance at $0.1 \mathrm{~mm}$ depth of cut as compared to the lower $0.05 \mathrm{~mm}$ depth of cut and the higher $0.12 \mathrm{or} 0.15 \mathrm{~mm}$ depth of cut. Secondly, like CC method, the cutting performance in UEVC increases with the decrease of the feed rate and cutting speed. The CC tests have also been carried out to compare performance of CC with UEVC method.
\end{abstract}

\section{Introduction}

As a typical nickel-based superalloy, Inconel 718 is widely used in the aerospace, gas turbine, and automobile industries for the high temperature strength and high corrosion resistance [1]. However, the mentioned properties are responsible for poor machinability of the Inconel 718 from various points of view such as surface quality and tool wear [2-4]. Nickel alloy is difficult to cut due to rapid work hardening. Much tool failure and serious tool wear in cutting of superalloy have been regarded as a challenging problem for modern traditional manufacture [2].

Ultrasonic elliptical vibration cutting (UEVC) was first introduced by Shamoto and Moriwaki in 1994 [5]. Through constant development in the last decade, this technique has been proven to be a promising method in terms of almost all cutting performances in cutting of various difficult-tocut materials [6-9]. Compared with the conventional cutting (CC) and ultrasonic vibration cutting, the UEVC have many advantages such as less cutting forces, longer tool life, and better surface finish [10, 11]. In Shamoto and Moriwaki's study [6], the UEVC was successfully used in ultraprecision cutting of hardened steel, such as ultraprecision cutting of a spherical die and a flexible microstructure and ultraprecision microgrooving. Suzuki and coworkers [12] cut a specially developed tungsten alloy with SCD tools in the ultraprecision UEVC method. Suzuki et al's research [13] carried out some ultraprecision microgrooving experiments on sintered WC using SCD tools to study the basic effects of UEVC on the ductile micromachining process. In Li and Zhang's studies [14], they obtained surface roughness $R_{a}$ of $0.08 \mu \mathrm{m}$ on an aluminium alloy using PCD tools in the ultraprecision UEVC cutting experiments. However, ultraprecision machining cannot be widely applied in industrial production for the limitations of ultraprecision machining equipment and technical requirements. The selected cutting parameters (cutting speed, feed rate, and depth of cut) in mentioned studies cannot be implemented in general lathes.

Wang and his team carried out several experiments to find out whether ultrasonic vibration was suitable for cutting of Inconel 718 in high cutting speed by using ultrasonic elliptical vibrations [15]. The effects of cutting speed on cutting force and cutting temperature in both CC and UEVC were reported. But the wear of cutting tools in the process was not studied in the paper. Moreover, the economic feasibility for both CC and UEVC methods in cutting of Inconel 718 has never been well studied. 


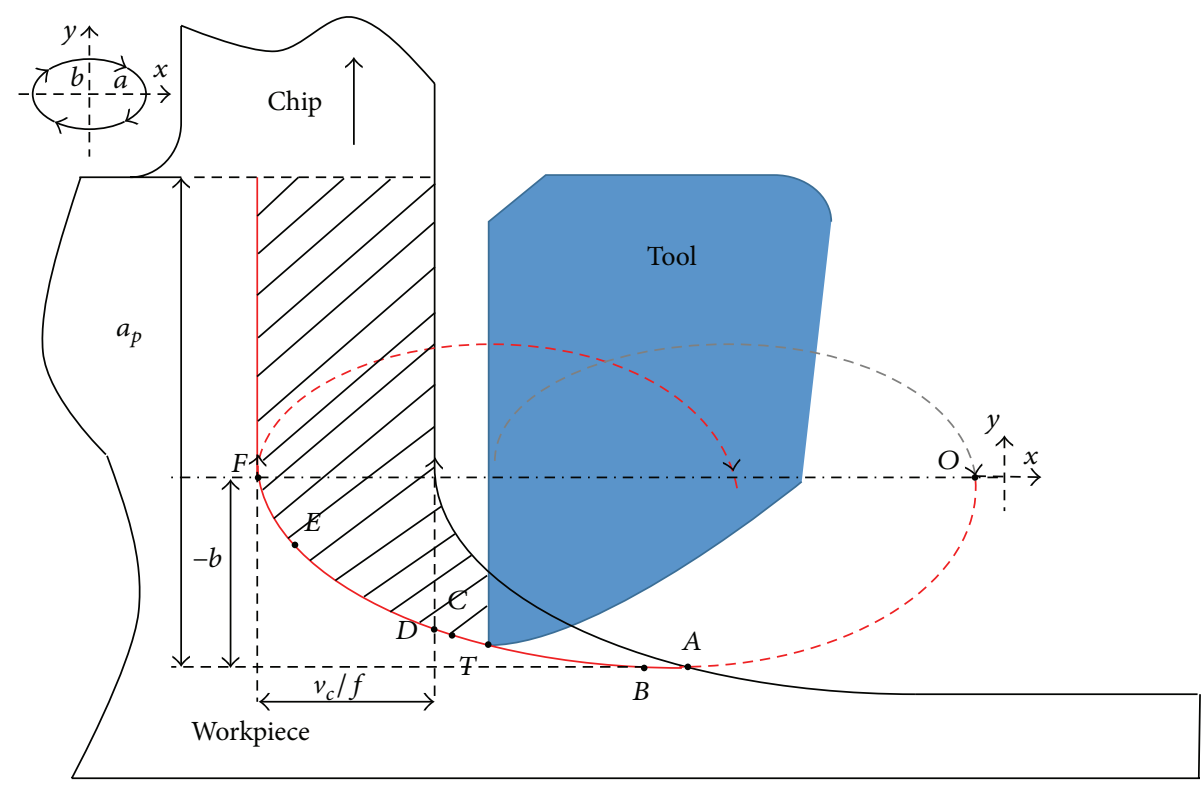

FIgURe 1: Principle of the UEVC method.

Literature review has shown that very few investigations about cutting of Inconel 718 using the UEVC method with PCD coated tool have been reported up till now. And the effects of cutting parameters such as cutting speed, feed rate, and depth of cut on cutting performance in UEVC method have not been reported. This paper aims to demonstrate an experimental study on UEVC of Inconel 718 with PCD coated tools using a new type UEVC system. Several cutting tests have been carried out to study the effect of cutting parameters in the UEVC method in terms of surface roughness and tool flank wear. Then the cutting condition at which the UEVC method performed better is applied to the CC method to compare the cutting performance between the UEVC method and CC method. The comparison of cost between the UEVC and the CC methods is also studied in this paper.

\section{The UEVC Principle}

During the UEVC process, an ultrasonic elliptical vibrator is applied to make the tool tip vibrated elliptically $[5,6]$. The schematic of the UEVC is shown in Figure 1. The elliptical vibration cutting, so named, is used at conventional cutting speed with a commercially available ultraprecision lathe by utilizing a newly developed ultrasonic vibrator which can generate the elliptical vibration at an ultrasonic frequency. $A$ is the initial position of the cutting process. $B$ is the lowest point of the cutting cycle. After reaching the crossover point $C$, tool nose finally reaches the point $F$ at the end of the cutting cycle. As shown in Shamoto and Moriwaki's work [5], the chip is pulled up by the tool rake face. The so-called depth of cut $\left(a_{p}\right)$ is always measured from the bottom of the vibration cycle to the workpiece free surface. When the tool is vibrated at an angular frequency $\omega$ and the workpiece is fed at a nominal cutting speed $v_{c}$, the tool path relative to the workpiece is expressed by $x$ - and $y$-coordinates of the tool position as

$$
\begin{aligned}
& x(t)=a \cos (\omega t)-v_{c} t, \\
& y(t)=b \cos (\omega t+\varphi),
\end{aligned}
$$

where $a$ is the amplitude of cutting direction vibration (i.e., $x$ axis), $b$ is the amplitude of the chip flow direction vibration (i.e., $y$-axis), $t$ is the time, and $\varphi$ is the phase shift between the two vibration modes. The angular frequency $\omega$ can be derived from the vibration frequency $f$ as

$$
\omega=2 \pi f
$$

\section{Experimental Details}

In this paper, a new type UEVC system was introduced. Cutting mechanism of the UEVC system consists of two orthogonal vibration arms. The mounting of two vibration arms was designed strictly according to the standard dimension of four-station tool carrier for guaranteeing easy installation of the mechanism. The UEVC system is shown in Figure 2. Transducer and ultrasonic horn are inside the sleeves.

The modal analysis of the designed ultrasonic system was carried out through ABAQUS simulation software. The modal analysis chart is shown in Figure 3. The resonance frequency of the tool holder and the cutting tool is over $30 \mathrm{kHz}$, which is satisfied with experiment requirement.

The ultrasonic signal generator that sets the output frequency in the cutting experiments shown in Figure 4 can output two sinusoidal signals of random phase difference, arbitrary amplitude, and random frequency. The amplitude of vibration excitation source should be chosen in 8-20 $\mu \mathrm{m}$ 
TABLE 1: Chemical composition (\%).

\begin{tabular}{lcccccccccc}
\hline $\mathrm{C}$ & $\mathrm{Mn}$ & $\mathrm{Si}$ & $\mathrm{Ti}$ & $\mathrm{Al}$ & $\mathrm{Co}$ & $\mathrm{Mb}$ & $\mathrm{Cb}$ & $\mathrm{Fe}$ & $\mathrm{Cr}$ & $\mathrm{Ni}$ \\
\hline 0.08 & 0.35 & 0.35 & 0.6 & 0.8 & 1.0 & 3.0 & 5.0 & 17.0 & 19.0 & 52.82 \\
\hline
\end{tabular}

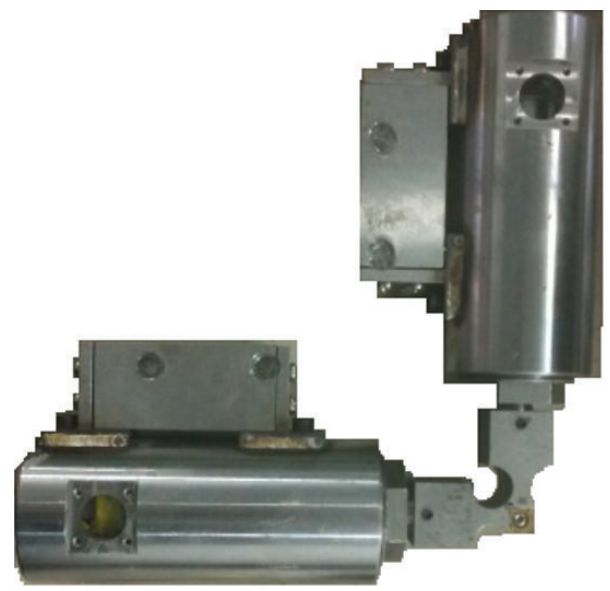

Figure 2: The UEVC system.

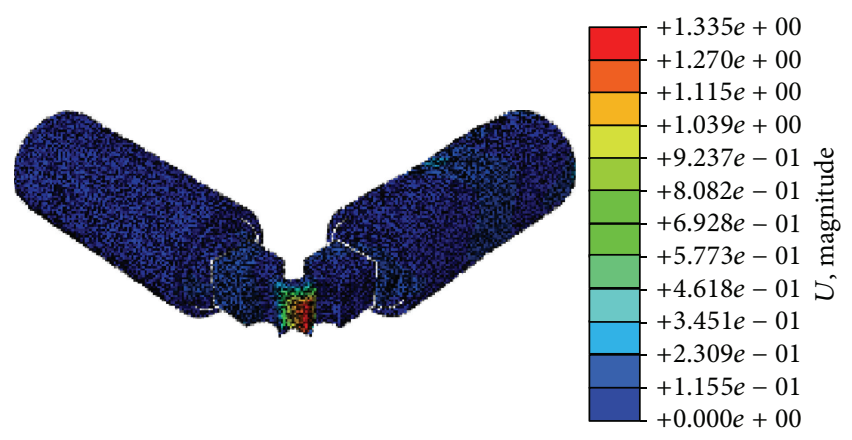

FIGURE 3: Modal analysis of UEVC system.

for improving cutting performance, enhancing machining accuracy, and reducing surface roughness of parts [16]. FZ30-H30-Z4 power type ultrasonic vibrator with maximum output power of $700 \mathrm{~W}$ and maximum output amplitude of $16 \mu \mathrm{m}$ is selected according to machining parameters decision, cutting forces, vibrational frequency, and output amplitude.

The following cutting experiments were carried out on the CA6140 lathe with the proposed UEVC system. The cutting experiment with the UEVC system is shown in Figure 5.

Inconel 718 with hardness of $48 \mathrm{HRC}$ is used as work material. Table 1 shows the chemical composition of Inconel 718 alloy.

In the experiments, diameter of workpieces was $40 \mathrm{~mm}$. Table 2 gives detailed specifications of workpiece, cutting tools, and machining parameters used for the experiments. The vibrational frequency and amplitude were fixed at $30 \mathrm{kHz}$. The range of cutting speeds was set below the
TABLE 2: Experimental specifications.

\begin{tabular}{lc}
\hline Workpiece & Inconel 718 \\
\hline Cutting tool & PCD coated tool \\
Cutting peed $v_{c}(\mathrm{~m} / \mathrm{min})$ & $10,13,16,19$ \\
Feed rate $f(\mathrm{~mm} / \mathrm{r})$ & $0.08,0.1,0.15,0.2$ \\
Depth of cut $a_{p}(\mathrm{~mm})$ & $0.05,0.1,0.12,0.15$ \\
Frequency $(\mathrm{kHz})$ & 30 \\
Amplitude in $x$-axis & $8 \mu \mathrm{m}$ \\
Amplitude in $y$-axis & $4 \mu \mathrm{m}$ \\
Coolant & Dry \\
\hline
\end{tabular}

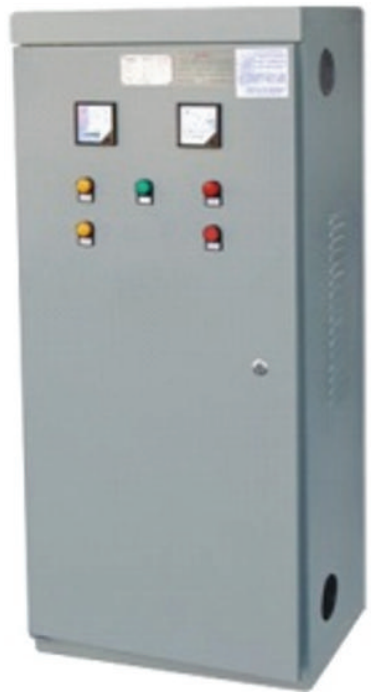

FIGURE 4: Ultrasonic signal generator.

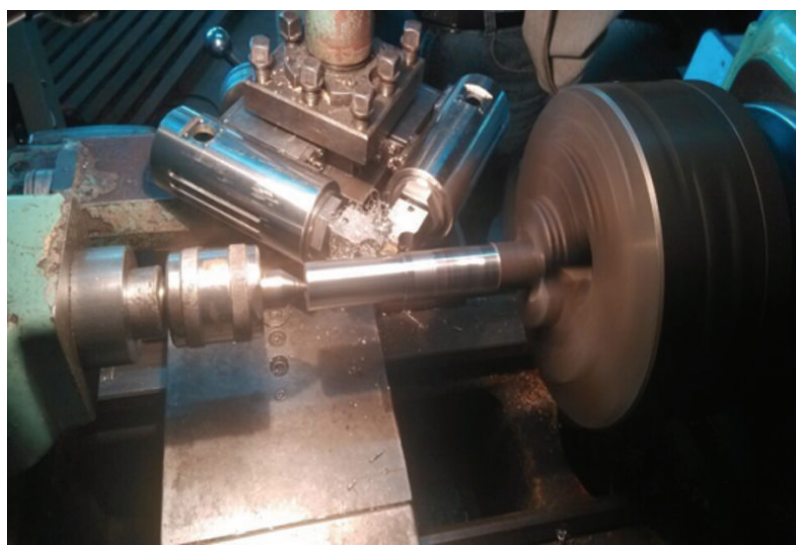

FIgURE 5: Cutting experiment with the UEVC system.

maximum tool vibration speed so that the separating type vibration cutting can be kept.

Outer diameter cutting was carried out for the experiments using Mitsubishi PCD coated tools. The photo of cutting tool is shown in Figure 6. Table 3 shows the details of cutting tool. 
TABLE 3: Details of cutting tool.

\begin{tabular}{lc}
\hline Cutting tool material & Polycrystalline diamond \\
\hline Cutting edge length $L(\mathrm{~mm})$ & 12 \\
Inscribed circle diameter $(\mathrm{mm})$ & 12.7 \\
Corner radius $r_{n}(\mathrm{~mm})$ & 0.4 \\
Nose angle $\left(^{\circ}\right)$ & 80 \\
Tool thickness $S(\mathrm{~mm})$ & 4.76 \\
\hline
\end{tabular}

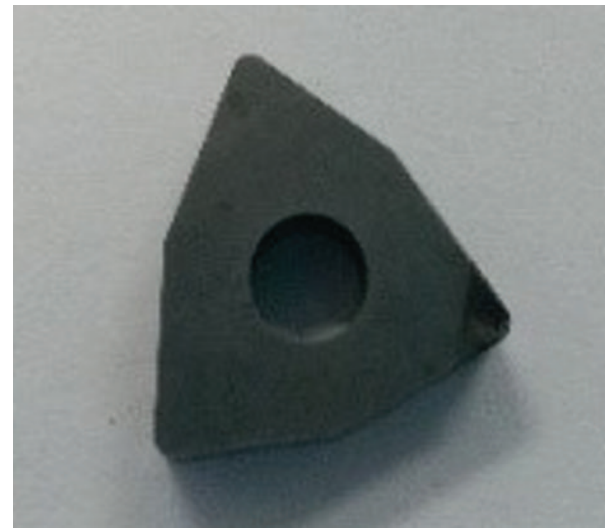

FIgURE 6: Photo of cutting tool.

\section{Results and Analysis}

4.1. Effect of Machining Parameters on Tool Flank Wear. The effects of the machining parameters on width of tool flank wear are shown in Figure 7. Figure 7(a) presents the effect of depth of cut on flank wear with a cutting speed of $16 \mathrm{~m} / \mathrm{min}$ and a feed rate of $0.2 \mathrm{~mm} / \mathrm{r}$. It can be seen obviously from Figure 7 (a) that the width of flank wear at $0.05 \mathrm{~mm}$ depth of cut is lower than other higher depth of cuts. This is because rubbing action at the tool nose is playing a leading effect at the beginning of process when the tool nose chipped off under the depth of cut. The flank wear width was small at $0.05 \mathrm{~mm}$ depth of cut because small depth of cut gives a small width of flank wear in the cutting direction.

The effect of cutting speed was studied in Figure 7(b) with a depth of cut of $0.1 \mathrm{~mm}$ and a feed rate of $0.08 \mathrm{~mm} / \mathrm{r}$. The effect of feed rate was shown in Figure $7(\mathrm{c})$ with a depth of cut of $0.1 \mathrm{~mm}$ and a cutting speed of $16 \mathrm{~m} / \mathrm{min}$. Figures 7 (b) and 7(c) demonstrate that the flank wear increases with the increase in both the cutting speed and the feed rate. The result for the effect of cutting speed can be explained by the limitation of cutting speed during the UEVC process. The performance of UEVC becomes the same as CC if the cutting speed is set higher than the maximum tool vibration speed. Moreover, the possibility of interaction between the tool flank and the machined workpiece behind the tool nose increases with the increase of cutting speed. This will result in more flank wear during the UEVC process $[5,17]$.

As discussed in the previous part, it is obvious that Figure $8(d)$ shows the smallest width of flank wear $(0.1 \mathrm{~mm}$ depth of cut, $0.08 \mathrm{~mm} / \mathrm{r}$ feed rate, and $10 \mathrm{~m} / \mathrm{min}$ cutting speed). So it can be determined that the PCD coated tool's life increases with the decrease in both the cutting speed and the feed rate in UEVC of Inconel 718.

4.2. Effect of Machining Parameters on Surface Roughness. Surface roughness of machined parts plays an important role in manufacture field for influencing the tribological, frictional, and assembly characteristics of products. In this study of UEVC process, the surface profile is generated by 2 marks: feed marks along the feed direction and the vibration marks along the cutting direction. The theoretical surface roughness formed by the vibration marks along the cutting direction was introduced by Shamoto and Moriwaki [5]:

$$
R_{\mathrm{th}}^{V}=b \cos \left(\omega t_{A}+\varphi\right)+b,
$$

where $t_{A}$ is the time instant when the tool edge starts contacting point $A$. The calculative method for $t_{A}$ has also been introduced in the study of Ulutan and Ozel [4]:

$$
\begin{aligned}
& a \cos \left(\omega t_{A}\right)-a \cos \left(\omega t_{C}\right)+v\left(t_{C}-t_{A}\right)=\frac{2 \pi v_{c}}{\omega}, \\
& b \cos \left(\omega t_{A}+\varphi\right)=b \cos \left(\omega t_{C}+\varphi\right) .
\end{aligned}
$$

The theoretical surface roughness formed by the feed marks was introduced by Vyas and Shaw in 1999 [9]. It can be expressed as

$$
R_{\mathrm{th}}^{f}=\frac{f^{2}}{8 r_{n}},
$$

where $r_{n}$ is the tool nose radius shown in Table 3. Based on (3) and (5), the theoretical surface roughness $R_{\text {th }}$ of the UEVC machined surface should be the superposition of the two examples of roughness above: $R_{\mathrm{th}}^{V}$ in the cutting direction and $R_{\text {th }}^{f}$ in the feed direction.

The effect of the machining parameters on surface roughness values $\left(R_{a}\right.$ and $\left.R_{z}\right)$ under different machining conditions was shown in Figure 9. It can be seen from Figure 9(a) that both $R_{a}$ and $R_{z}$ are lower at $0.1 \mathrm{~mm}$ depth of cut compared to the other depth of cuts $(0.05 \mathrm{~mm}, 0.12 \mathrm{~mm}$, and $0.15 \mathrm{~mm}$ ) in the UEVC process. In general, the surface roughness increases with the increase of depth of cut just like the CC process. However, the tool failed at the beginning of the process at 0.05 depth of cut as shown in the earlier discussion. Because of the rubbing action at the tool nose, the worn cutting tool produced high surface roughness during the whole cutting process. In contrast, the cutting quality improved at $0.1 \mathrm{~mm}$ depth of cut as the flank wear much decreased at this depth of cut.

Figure 9 also shows that the surface roughness increases with the increase in both the cutting speed and the feed rate, just like the $\mathrm{CC}$ process. The photographs of machined surface magnified 200 times are shown in Figure 10. Figures 10(a) and 10(b), 10(a) and 10(c), and 10(c) and 10(d) show comparisons of surface finish for variation in the depth of cut, feed rate, and cutting speed, respectively. According to the comparisons above, it can be finally determined that 


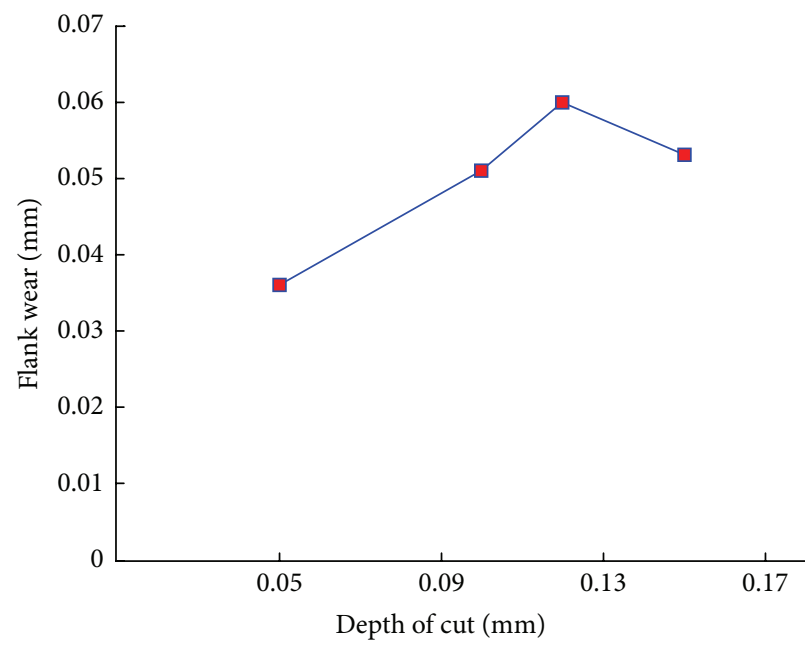

(a)

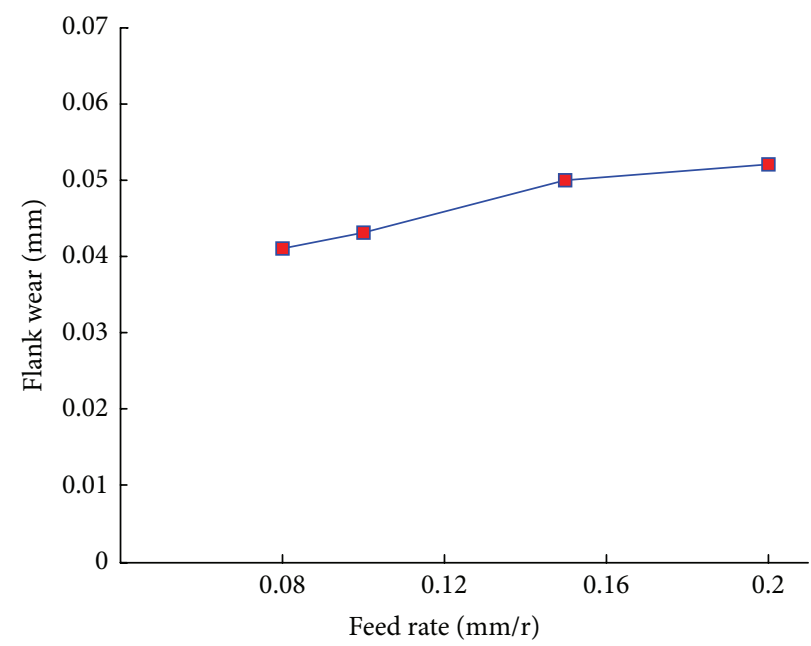

(b)

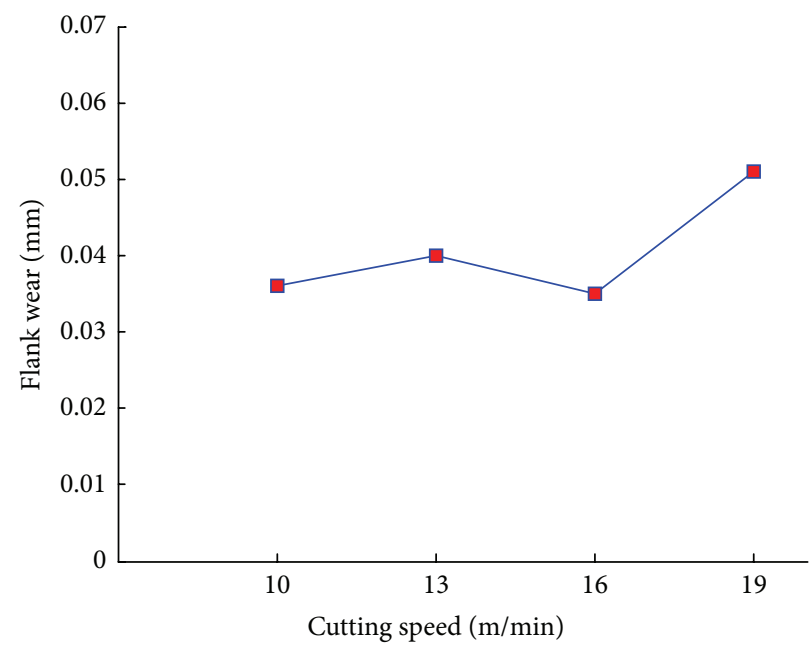

(c)

FIGURE 7: The effects of the cutting parameters on flank wear.

the parameter combination of $0.1 \mathrm{~mm}$ depth of cut, $0.08 \mathrm{~m} / \mathrm{r}$ feed rate, and $10 \mathrm{~m} / \mathrm{min}$ cutting speed achieves better cutting performance as compared to the other conditions tested in the UEVC process.

4.3. Wear Characteristics and Chip Analysis. In order to understand the mechanics of UEVC process, the tool wear progression against the cutting time under the cutting condition $(0.12 \mathrm{~mm}$ depth of cut, $0.2 \mathrm{~mm}$ feed rate, and $16 \mathrm{~m} / \mathrm{min}$ cutting speed) was introduced. Figure 11 shows the tool wear with respect to the cutting time. Figure 11(a) shows that the tool wear at the beginning of cutting process $(5 \mathrm{~min})$ is not obvious. Along with the processing, beyond this cutting time, the flank face of cutting tool shown in Figures 11(b) and 11(c) started wearing out badly. After that the tool wear moves slowly during 30 min cutting time as observed in Figures 11(d) and $11(\mathrm{e})$. It is obvious that the rake face of the tool at $15 \mathrm{~min}$,
$20 \mathrm{~min}$, and $30 \mathrm{~min}$ cutting time has the same wear patterns as shown in Figures 11(c), 11(d), and 11(e). It also means that the tool rake face sustains many shocks from the workpiece because of the continuous vibration cycles. As the Inconel 718 material was tougher due to its high temperature strength and high corrosion resistance, the cutting tools cannot sustain so many impacts for a long time. So the cutting tool started chipping from the tool nose area at the beginning and finally the wear progressed towards flank face of the tool with the process of UEVC. That is to say, the continuous vibration plays dominant role at the beginning in the wear mechanism. At 40 min of cutting time, as shown in Figure 11(f), the tool nose turned into flat. The rubbing action between the tool and the workpiece started impacting the tool wear in every vibration cycle. By this time, the abrasive wear is the main wear pattern. The abrasive wear is because the impurities and hard particles exist in the workpiece material [18], such as carbon, nitride, and oxide compounds. 


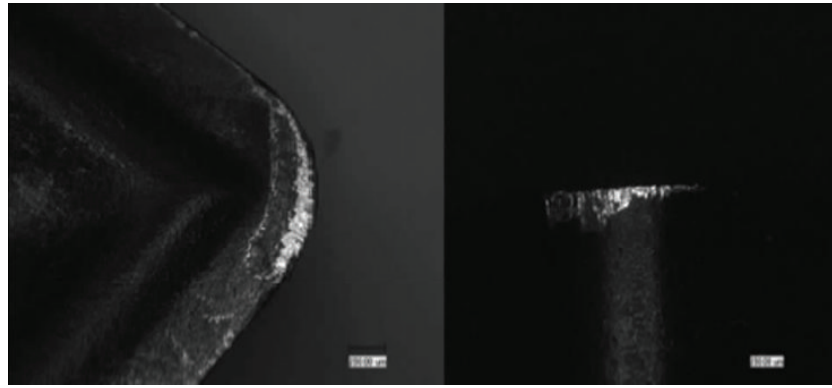

(a) $0.1 \mathrm{~mm}$ depth of cut, $0.2 \mathrm{~mm}$ feed rate, and $16 \mathrm{~m} / \mathrm{min}$ cutting speed

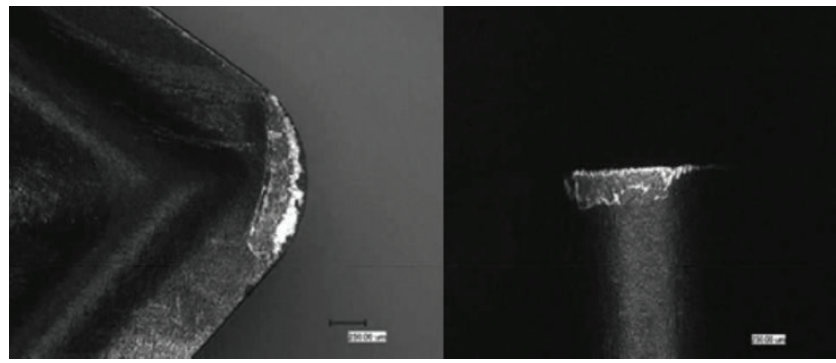

(b) $0.12 \mathrm{~mm}$ depth of cut, $0.2 \mathrm{~mm}$ feed rate, and $16 \mathrm{~m} / \mathrm{min}$ cutting speed

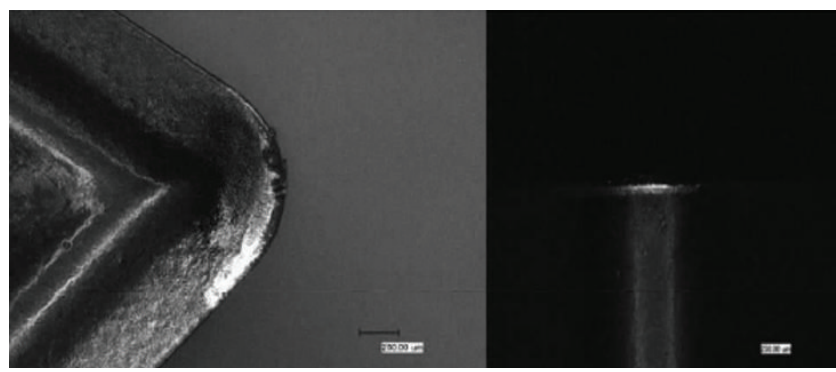

(c) $0.1 \mathrm{~mm}$ depth of cut, $0.08 \mathrm{~mm}$ feed rate, and $16 \mathrm{~m} / \mathrm{min}$ cutting speed

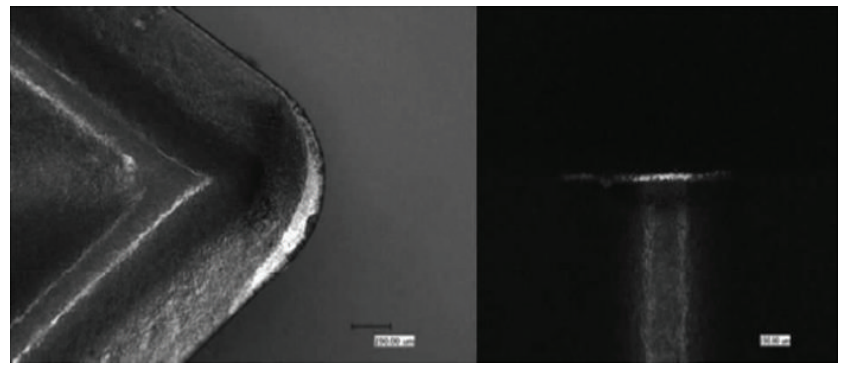

(d) $0.1 \mathrm{~mm}$ depth of cut, $0.08 \mathrm{~mm}$ feed rate, and $10 \mathrm{~m} / \mathrm{min}$ cutting speed

Figure 8: Photographs of the flank wear under different cutting conditions.

The photographs of cutting chips produced at $5 \mathrm{~min}$ and 20 min cutting time were shown in Figures 12(a) and 12(b), respectively. It can be found from Figure 12(a) that the cutting chips produced at $5 \mathrm{~min}$ are broken and there are no grooves or abrasive traces. But the grooves and abrasive traces generated on the surfaces of cutting chip produced at $20 \mathrm{~min}$ are shown in Figure 12(b). The phenomena above can also explain that the wear mechanism at the beginning was dominated by the continuous vibration impacts and failed because of the abrasive wear between the tool and the workpiece in the latter phase.

4.4. Comparison between the UEVC Process and the CC Process. A comparison between the UEVC and the CC methods was made in terms of the economic feasibility, flank wear width, and the surface roughness $\left(R_{a}\right.$ and $\left.R_{z}\right)$. The experimental results by comparison are shown in Figure 11. Given the current economic situation, the cost of the cutting process against the benefits it will bring should be taken into consideration. Tool life is considered as the most important element for the investigation of economic feasibility of metal machining. This study is to confirm which method is more economic for machining Inconel 718 by PCD coated tools. The comparison of total cutting cost per part between the two processes was made based on Gilbert's study $[19,20]$.

The cost analysis was studied for cutting of a cylindrical workpiece with a diameter $(d)$ of $30 \mathrm{~mm}$ and a length of cut (l) of $60 \mathrm{~mm}$ under the parameter combination of $0.1 \mathrm{~mm}$ depth of cut, $0.08 \mathrm{~m} / \mathrm{r}$ feed rate, and $10 \mathrm{~m} / \mathrm{min}$ cutting speed. Assuming that the labor charge is $¥ 100$ per hour, the machine charge is $¥ 10$ per hour, and the overhead is $¥ 10$ per hour; the total cost of the machining time and labor $(x)$ is about $¥ 120$ per hour. With these parameters, the machining time per part can be calculated by the following formula:

$$
T_{c}=\frac{\pi d l}{1000 v f},
$$

where $d$ is the diameter of workpiece $(\mathrm{mm}), l$ is the axial length of the work to be cut $(\mathrm{mm}), v$ is the cutting speed $(\mathrm{m} / \mathrm{min})$, and $f$ is the feed rate $(\mathrm{mm} / \mathrm{r})$. Therefore, the labor and machining costs are acquired from the product of $\left(x T_{c}\right)$.

The changing time of tool per part includes the machine down time when the operator changes the tools. If $T_{d}$ is the down time in minutes to change the tool and the workpiece and $T$ is tool life for one cutting edge, then the cost for tool changing per part is given by the following formula:

$$
\text { tool changing cost per part }=\left(x T_{d} \frac{T_{c}}{T}\right) .
$$

Unit price of the PCD coated tools is $¥ 120$. The average cost of a single cutting edge $(y)$ is $¥ 120$. The tool cost per part is estimated by

$$
\text { tool cost per part }=\left(y \frac{T_{c}}{T}\right) .
$$

The total machining cost per part $(C)$ is the sum of the labor and machine costs, the tool changing cost, and the tool cost per part:

$$
C=x T_{c}+x T_{d} \frac{T_{c}}{T}+y \frac{T_{c}}{T} .
$$

Comparison of machining costs for UEVC and CC is shown in Table 4 . It can be seen obviously that the total machining cost per part in UEVC is much lower than that in CC. According to the results shown in Table 4, the total 


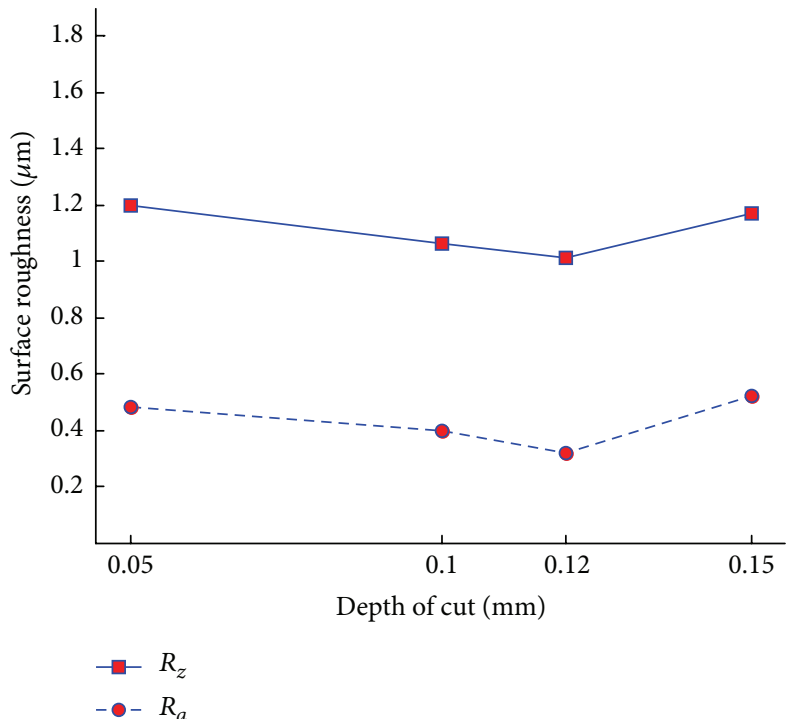

(a)

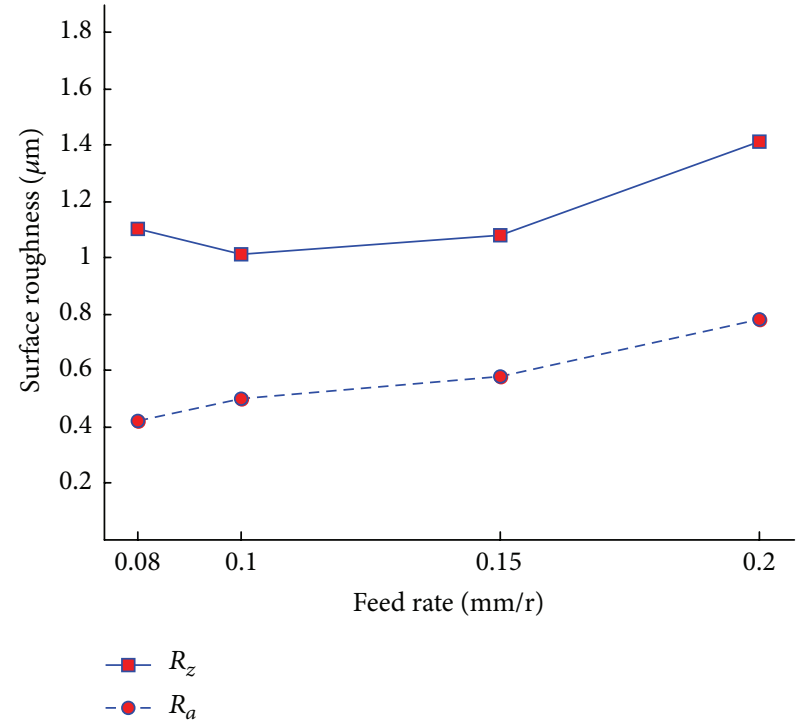

(b)

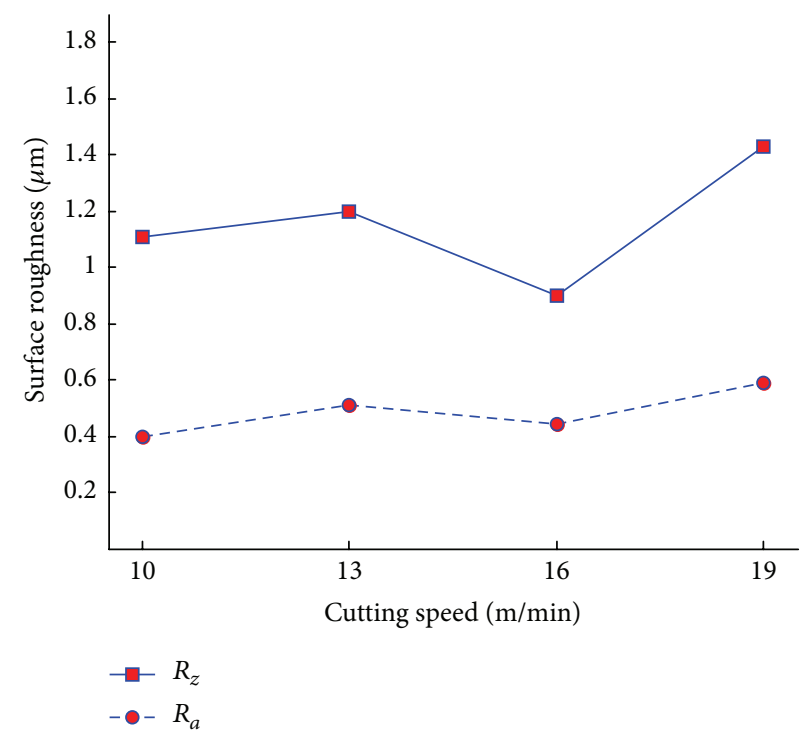

(c)

FIGURE 9: The effects of different cutting speeds, depth of cuts, and feed rates on surface roughness.

TABLE 4: Comparison of machining costs for UEVC and CC.

\begin{tabular}{lcc}
\hline Costs & CC & UEVC \\
\hline Machining time per part $\left(T_{c}\right)$ & $7.07 \mathrm{~min}$ & $7.07 \mathrm{~min}$ \\
Cost of machine and operator $(x)$ & $¥ 2 \mathrm{~min}^{-1}$ & $¥ 2 \mathrm{~min}^{-1}$ \\
Machining cost per part $\left(x T_{c}\right)$ & $¥ 14.14$ & $¥ 14.14$ \\
Machine down time $\left(T_{d}\right)$ & $5 \mathrm{~min}$ & $5 \mathrm{~min}$ \\
Tool life for single edge $(T)$ & $10.6 \mathrm{~min}$ & $17.4 \mathrm{~min}$ \\
Tool changing cost per part & $¥ 6.67$ & $¥ 4.06$ \\
Tool cost per part & $¥ 80.04$ & $¥ 48.76$ \\
Total machining cost per part & $¥ 100.84$ & $¥ 66.96$ \\
\hline
\end{tabular}

machining cost per part in UEVC is $66 \%$ of that in CC process.

As shown in Figure 13, the width of tool flank wear in CC process is much higher than that in UEVC. This is because much heat generates during the CC process. Depending on the depth of cut used, the flank wear increases with the rise of cutting temperature on the nose of cutting tool. In contrast, according to the study of Shamoto and Moriwaki [6], the UEVC method generated much smaller cutting forces during the process compared to the CC method, which directly reduces the generation of cutting heat in the tool-workpiece interface. Moreover, the reduction of continuous contact at the tool-workpiece interface due to intermittent cutting 


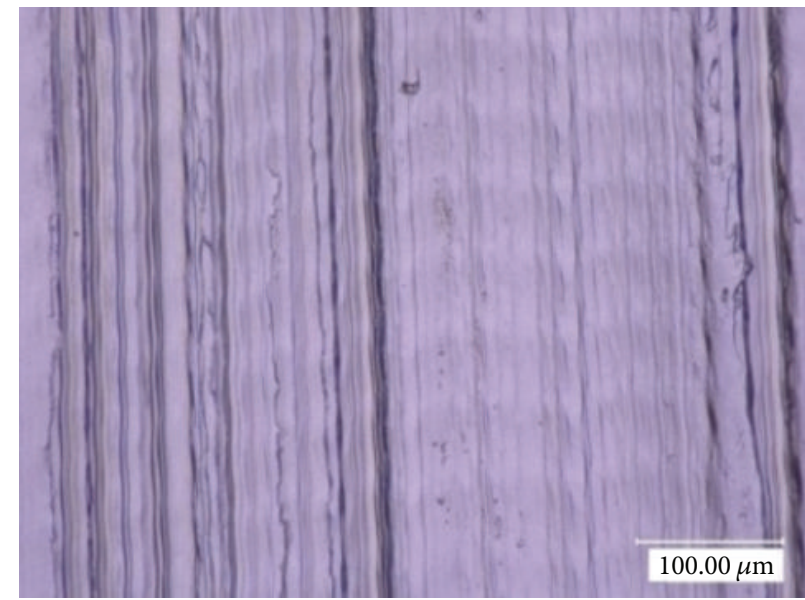

(a) $0.1 \mathrm{~mm}$ depth of cut, $0.2 \mathrm{~mm}$ feed rate, and $16 \mathrm{~m} / \mathrm{min}$ cutting speed

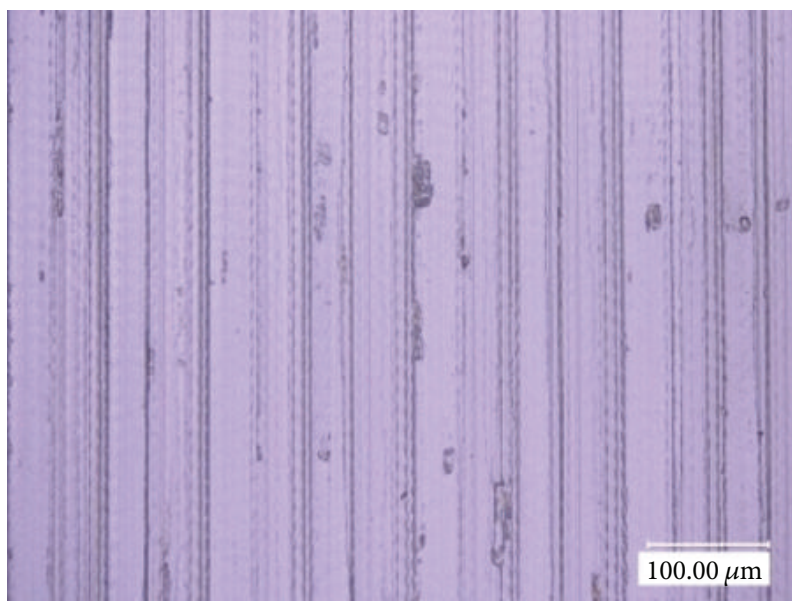

(c) $0.1 \mathrm{~mm}$ depth of cut, $0.08 \mathrm{~mm}$ feed rate, and $16 \mathrm{~m} / \mathrm{min}$ cutting speed

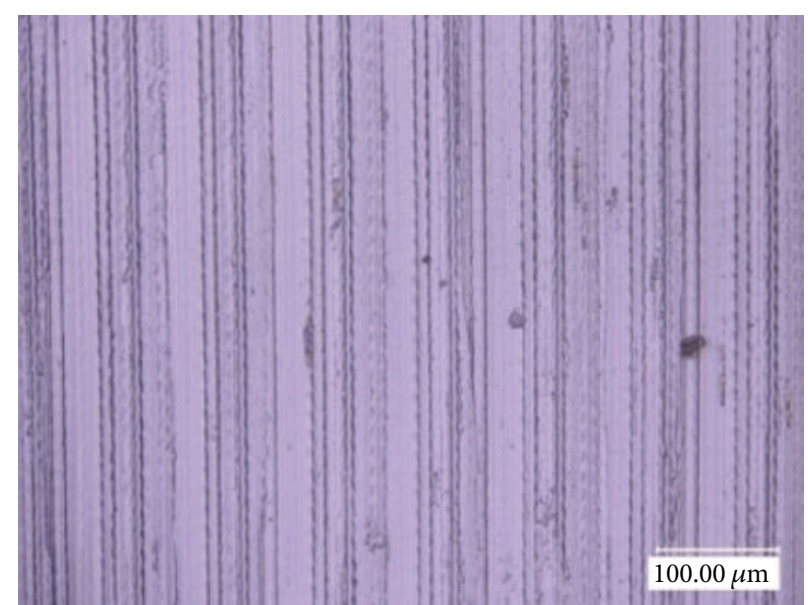

(b) $0.12 \mathrm{~mm}$ depth of cut, $0.2 \mathrm{~mm}$ feed rate, and $16 \mathrm{~m} / \mathrm{min}$ cutting speed

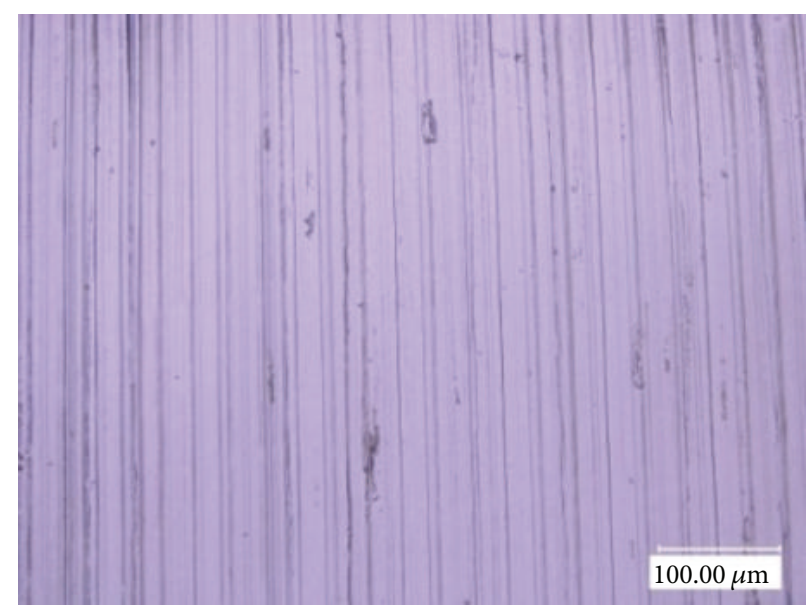

(d) $0.1 \mathrm{~mm}$ depth of cut, $0.08 \mathrm{~mm}$ feed rate, and $10 \mathrm{~m} / \mathrm{min}$ cutting speed

FIgURE 10: Photographs of the machined workpiece under different cutting conditions.

characteristics and the inhibition of built-up edge caused by the reversed thrust force keeps lower temperature between the tool and the workpiece. The low temperature can directly suppress the chemical diffusion and catalyzed graphitization in the cutting process and hence decrease the flank wear of diamond tools [21].

The average surface roughness $R_{a}$ of $0.42 \mu \mathrm{m}$ was obtained in the UEVC process, while $0.73 \mu \mathrm{m}$ was obtained in the CC process under the same cutting conditions. Brittle fractures were found on CC machined surface, which increase the surface roughness. In the UEVC process, many uninterrupted passes of the tool edge over the surface decrease the critical depth of cut, which leads to brittle mode cutting and improves the surface quality [22]. So the surface finish of Inconel 718 machined by UEVC method with the PCD tools can be improved.

\section{Conclusions}

The experimental test of UEVC of Inconel 718 by using PCD coated tools under different parameters was carried out in this paper. The effects of different cutting parameters on tool flank wear and surface roughness were examined. The comparisons of economic feasibility, machined surface finish, and flank wear in UEVC and CC methods were also made. According to the experimental findings above, some conclusions can be obtained as follows:

(1) In the UEVC process, the PCD coated tools used in cutting of Inconel 718 are able to obtain better performance at $0.1 \mathrm{~mm}$ depth of cut as compared to both the lower $0.05 \mathrm{~mm}$ depth of cut and the higher $0.12 \mathrm{~mm}$ depth of cut and $0.15 \mathrm{~mm}$ depth of cut.

(2) As in the CC process, cutting performance in the UEVC process improves with the decrease of both the cutting speed and the feed rate. In CC process, $R_{a}$ of $0.73 \mu \mathrm{m}$ was obtained, while the surface roughness in UEVC process can be achieved at $0.42 \mu \mathrm{m}$ under the same cutting conditions.

(3) The wear mechanism at the beginning was dominated by the continuous vibration impacts and failed 


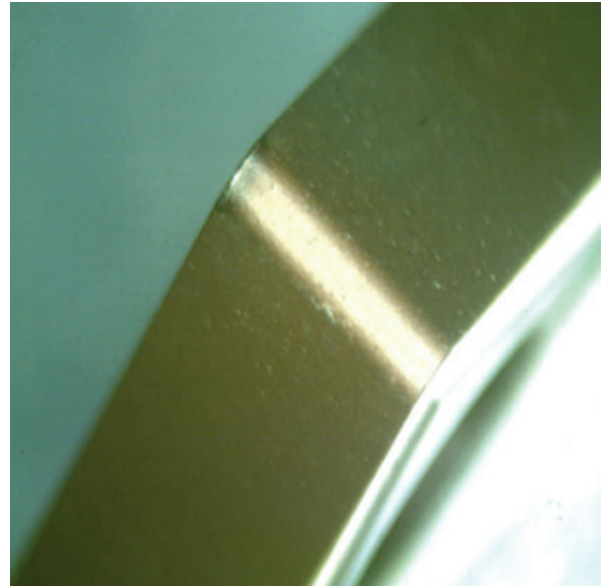

(a) $5 \mathrm{~min}$

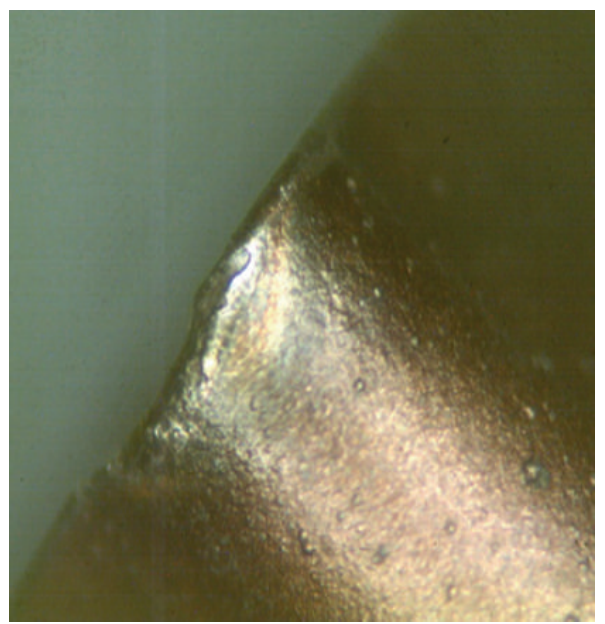

(c) $15 \mathrm{~min}$

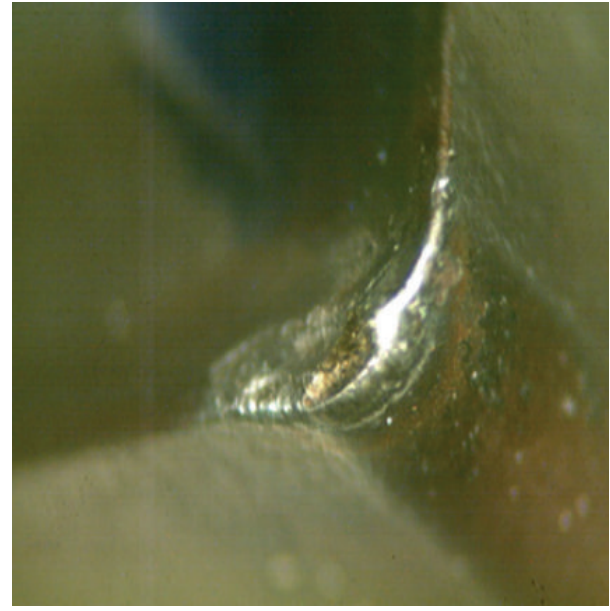

(e) $30 \mathrm{~min}$

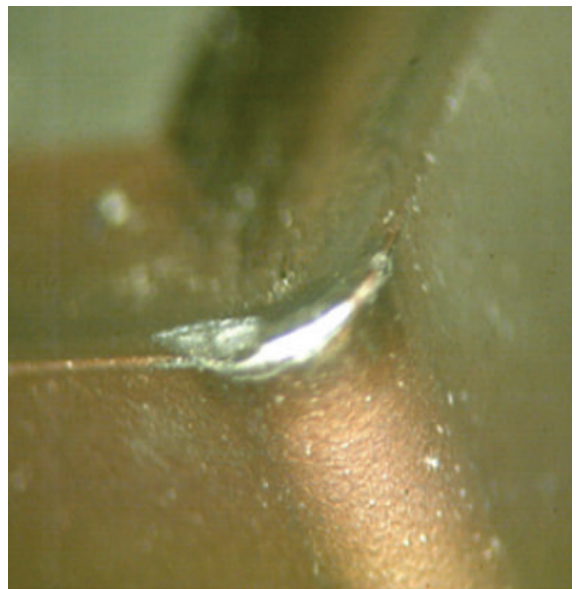

(b) $10 \mathrm{~min}$

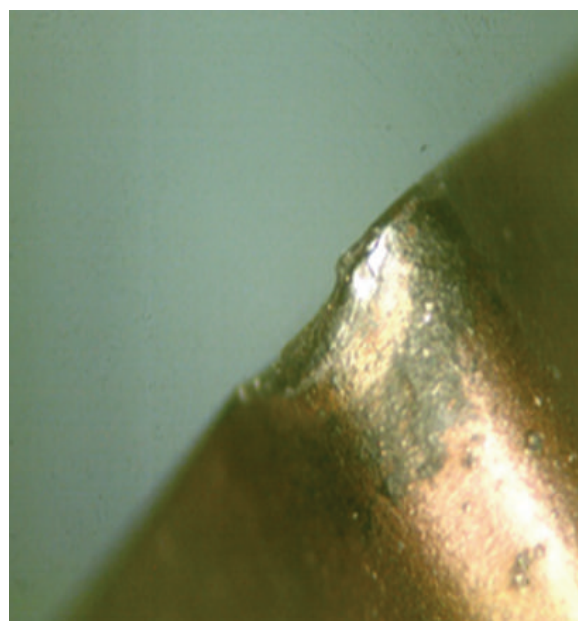

(d) $20 \mathrm{~min}$

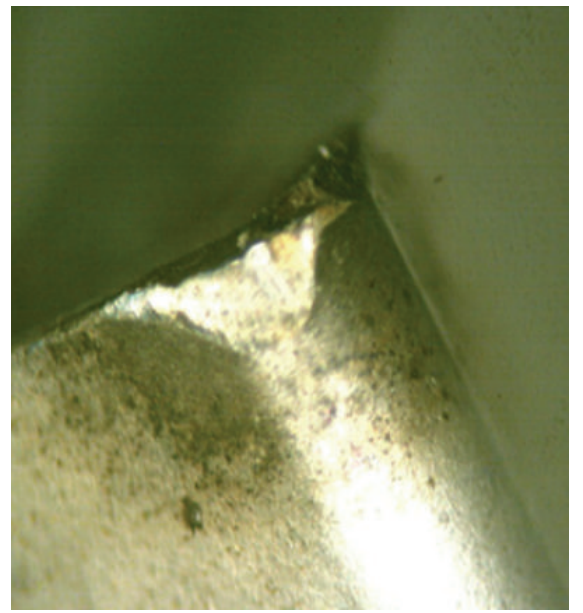

(f) $40 \mathrm{~min}$

FigURE 11: Photographs of tool wear at different cutting time $(0.12 \mathrm{~mm}$ depth of cut, $0.2 \mathrm{~mm}$ feed rate, and $16 \mathrm{~m} / \mathrm{min}$ cutting speed). 


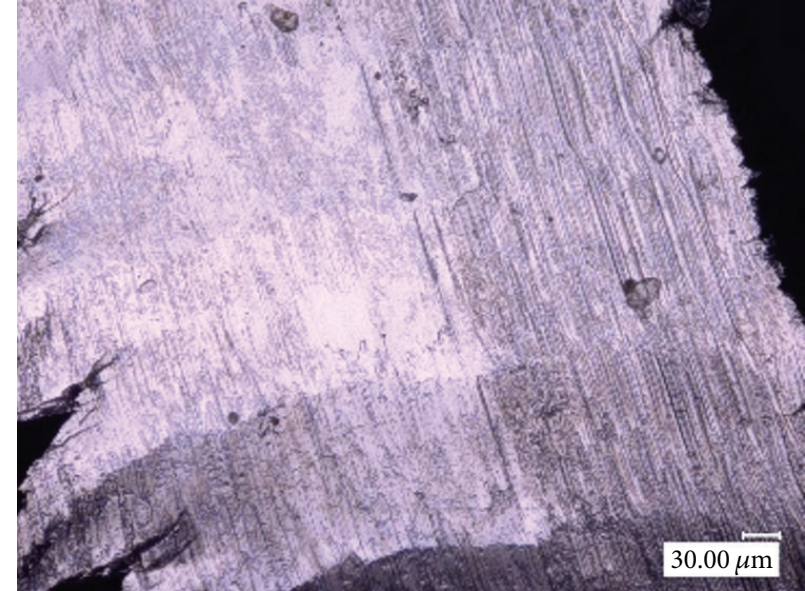

(a)

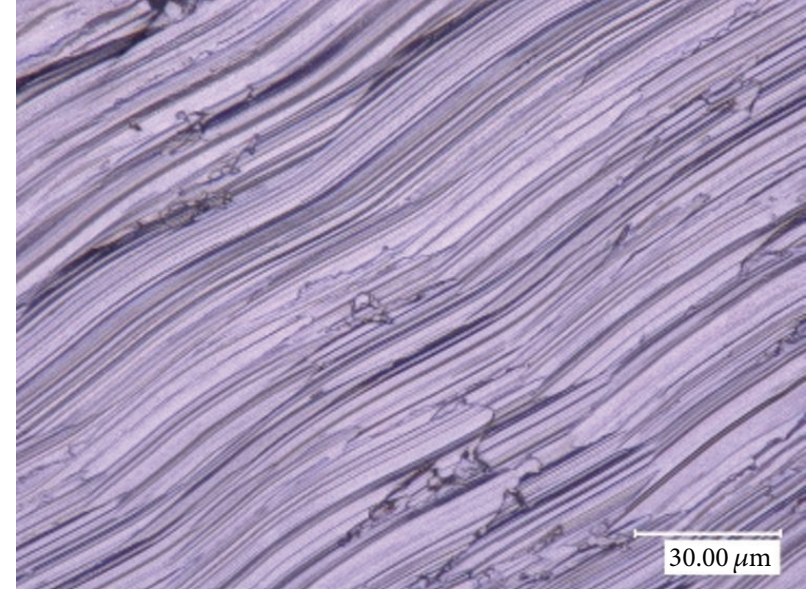

(b)

FIGURE 12: Photographs of cutting chip produced at (a) $5 \mathrm{~min}$ and (b) $20 \mathrm{~min}$.

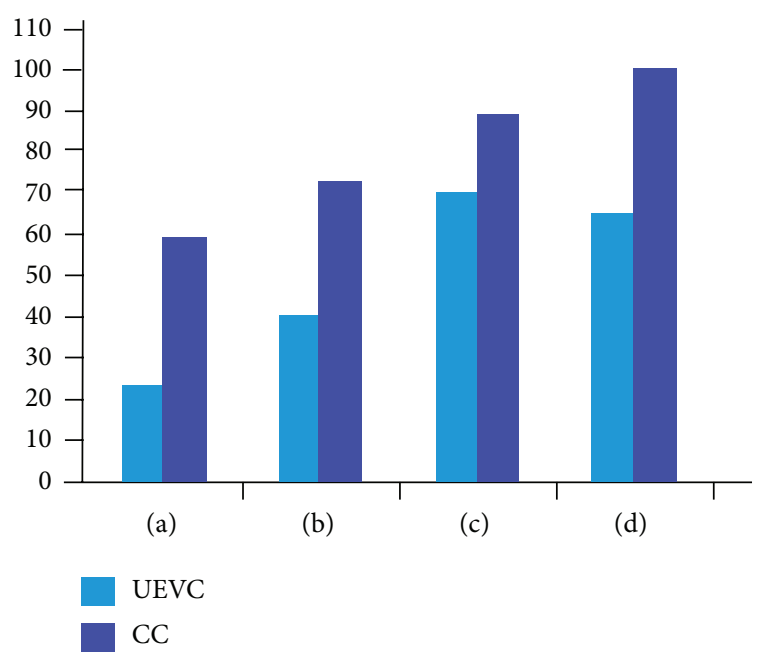

FIGURE 13: Comparison of (a) width of flank wear, $\mu \mathrm{m} \times 100$, (b) $R_{a}$, $\mu \mathrm{m} \times 100,(\mathrm{c}) R_{z}, \mu \mathrm{m} \times 100$, and (d) cost between the UEVC and the CC methods at a depth of cut of $0.1 \mu \mathrm{m}$, a feed rate of $0.08 \mu \mathrm{m} / \mathrm{r}$, and a cutting speed of $10 \mathrm{~m} / \mathrm{min}$.

because of the abrasive wear between the tool and the workpiece in the latter stage.

(4) The total machining cost per part in UEVC process is $66 \%$ of CC process.

(5) The results demonstrate that the PCD coated tools can be applied in cutting of Inconel 718 by using the UEVC process at low feed rate and low cutting speed to produce high quality surfaces with a low cost.

\section{Competing Interests}

The authors declare that they have no competing interests.

\section{Acknowledgments}

The authors are thankful for the financial support of this work and for the Shenyang Science and Technology Plan Projects (F16-205-1-05).

\section{References}

[1] R. S. Pawade, S. S. Joshi, P. K. Brahmankar, and M. Rahman, "An investigation of cutting forces and surface damage in highspeed turning of Inconel 718," Journal of Materials Processing Technology, vol. 192, pp. 139-146, 2007.

[2] E. O. Ezugwu, "Key improvements in the machining of difficultto-cut aerospace superalloys," International Journal of Machine Tools and Manufacture, vol. 45, no. 12-13, pp. 1353-1367, 2005.

[3] E. O. Ezugwu, J. Bonney, and Y. Yamane, "An overview of the machinability of aeroengine alloys," Journal of Materials Processing Technology, vol. 134, no. 2, pp. 233-253, 2003.

[4] D. Ulutan and T. Ozel, "Machining induced surface integrity in titanium and nickel alloys: a review," International Journal of Machine Tools and Manufacture, vol. 51, no. 3, pp. 250-280, 2011.

[5] E. Shamoto and T. Moriwaki, "Study on elliptical vibration cutting," CIRP Annals-Manufacturing Technology, vol. 43, no. 1, pp. 35-38, 1994.

[6] E. Shamoto and T. Moriwaki, "Ultraprecision diamond cutting of hardened steel by applying elliptical vibration cutting," CIRP Annals-Manufacturing Technology, vol. 48, no. 1, pp. 441-444, 1999.

[7] G. A. Volkov, V. A. Bratov, A. A. Gruzdkov, V. I. Babitsky, Y. V. Petrov, and V. V. Silberschmidt, "Energy-based analysis of ultrasonically assisted turning," Shock and Vibration, vol. 18, no. 1-2, pp. 333-341, 2011.

[8] J. H. Zhang, Y. Zhao, S. Zhang, F. Q. Tian, L. Guo, and R. Dai, "Study on effect of ultrasonic vibration on grinding force and surface quality in ultrasonic assisted micro end grinding of silica glass," Shock and Vibration, vol. 2014, Article ID 418059, 10 pages, 2014.

[9] A. Vyas and M. C. Shaw, "Mechanics of saw-tooth chip formation in metal cutting," Journal of Manufacturing Science and Engineering, vol. 121, no. 2, pp. 163-172, 1999. 
[10] N. Suzuki, A. Nakamura, E. Shamoto, K. Harada, M. Matsuo, and M. Osada, "Ultraprecision micromachining of hardened steel by applying ultrasonic elliptical vibration cutting," in Proceedings of the International Symposium on Micromechatronics and Human Science (MHS '03), pp. 221-226, Nagoya, Japan, October 2003.

[11] E. Shamoto, N. Suzuki, T. Moriwaki, and Y. Naoi, "Development of ultrasonic elliptical vibration controller for elliptical vibration cutting," CIRP Annals-Manufacturing Technology, vol. 51, no. 1, pp. 327-330, 2002.

[12] N. Suzuki, M. Haritani, J. Yang, R. Hino, and E. Shamoto, "Elliptical vibration cutting of tungsten alloy molds for optical glass parts," CIRP Annals-Manufacturing Technology, vol. 56, no. 1, pp. 127-130, 2007.

[13] N. Suzuki, S. Masuda, M. Haritani, and E. Shamoto, "Ultraprecision micromachining of brittle materials by applying ultrasonic elliptical vibration cutting," in Proceedings of the 2004 International Symposiumon on Micro-Nanomechatronics and Human Science (MHS '04), pp. 133-138, IEEE, 2004.

[14] X. Li and D. Zhang, "Ultrasonic elliptical vibration transducer driven by single actuator and its application in precision cutting," Journal of Materials Processing Technology, vol. 180, no. 1-3, pp. 91-95, 2006.

[15] Q. Wang, Y. Wu, J. Gu, D. Lu, Y. Ji, and M. Nomura, "Fundamental machining characteristics of the in-base-plane ultrasonic elliptical vibration assisted turning of inconel 718," Procedia CIRP, vol. 42, pp. 858-862, 2016.

[16] G. Dong and Y. Zhang, "Design of the ultrasonic vibration cutting tool," Machinery Design \& Manufacture, no. 2, pp. 242$244,2012$.

[17] C. Ma, E. Shamoto, T. Moriwaki, and L. Wang, "Study of machining accuracy in ultrasonic elliptical vibration cutting," International Journal of Machine Tools and Manufacture, vol. 44, no. 12-13, pp. 1305-1310, 2004.

[18] E. O. Ezugwu, Z. M. Wang, and A. R. Machado, “The machinability of nickel-based alloys: a review," Journal of Materials Processing Technology, vol. 86, no. 1-3, pp. 1-16, 1999.

[19] A. S. More, W. Jiang, W. D. Brown, and A. P. Malshe, "Tool wear and machining performance of $\mathrm{cBN}-\mathrm{TiN}$ coated carbide inserts and PCBN compact inserts in turning AISI 4340 hardened steel," Journal of Materials Processing Technology, vol. 180, no. 1-3, pp. 253-262, 2006.

[20] M. C. Shaw, Metal Cutting Principles, Oxford University Press, New York, NY, USA, 2005.

[21] C. Evans and J. B. Bryan, "Cryogenic diamond turning of stainless steel," CIRP Annals-Manufacturing Technology, vol. 40, no. 1, pp. 571-575, 1991.

[22] C. Nath, M. Rahman, and K. S. Neo, "Modeling of the effect of machining parameters on maximum thickness of cut in ultrasonic elliptical vibration cutting," ASME Journal of Manufacturing Science and Engineering, vol. 133, no. 1, Article ID 011007, 2011. 


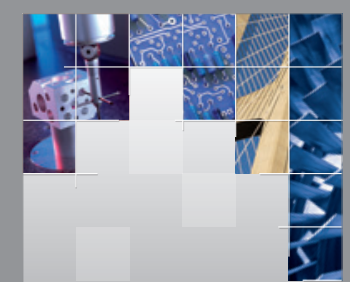

\section{Enfincering}
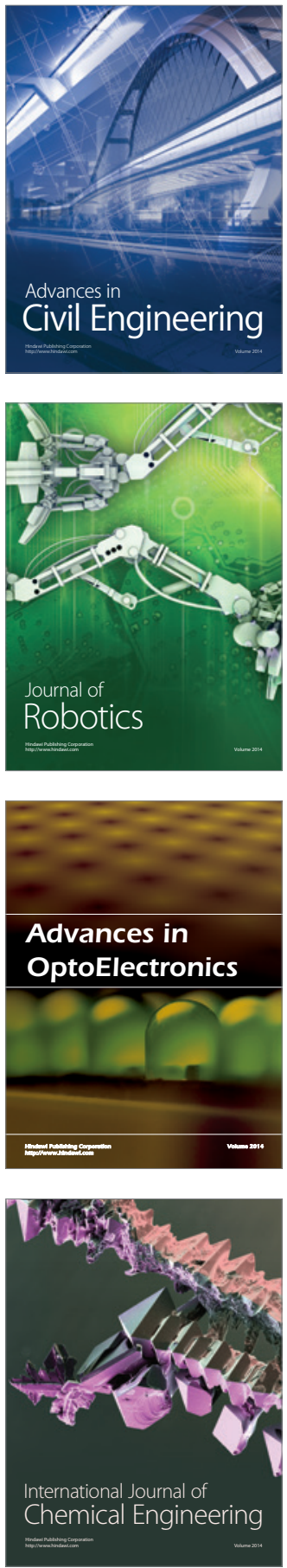

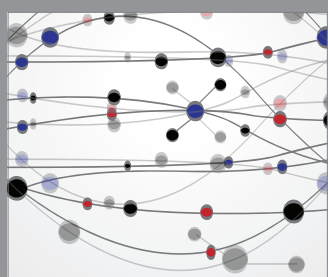

The Scientific World Journal

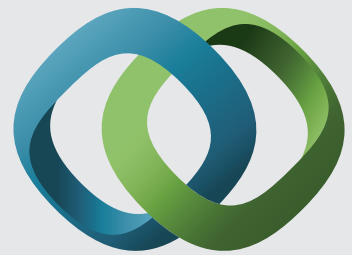

\section{Hindawi}

Submit your manuscripts at

http://www.hindawi.com
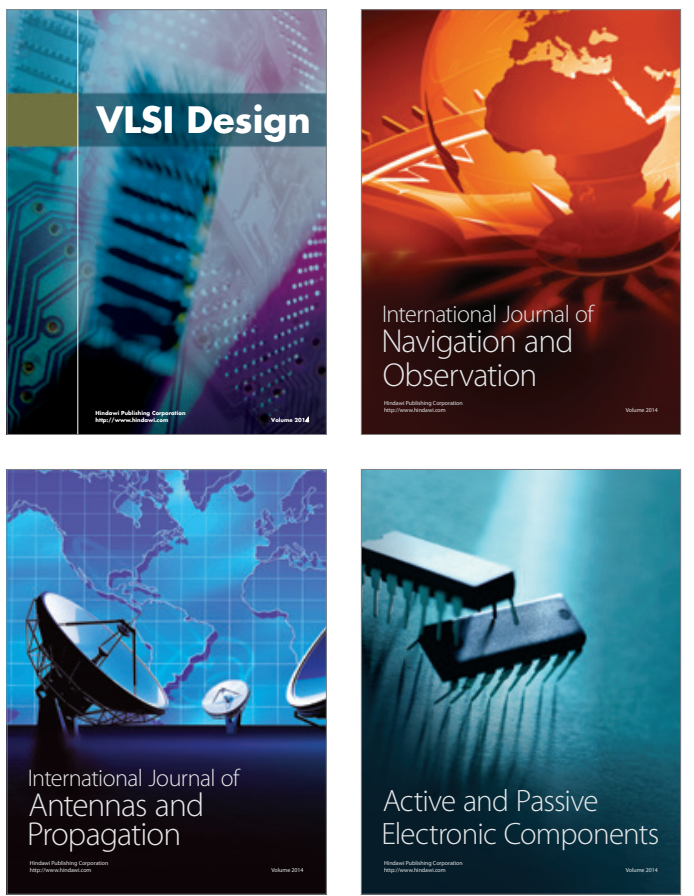
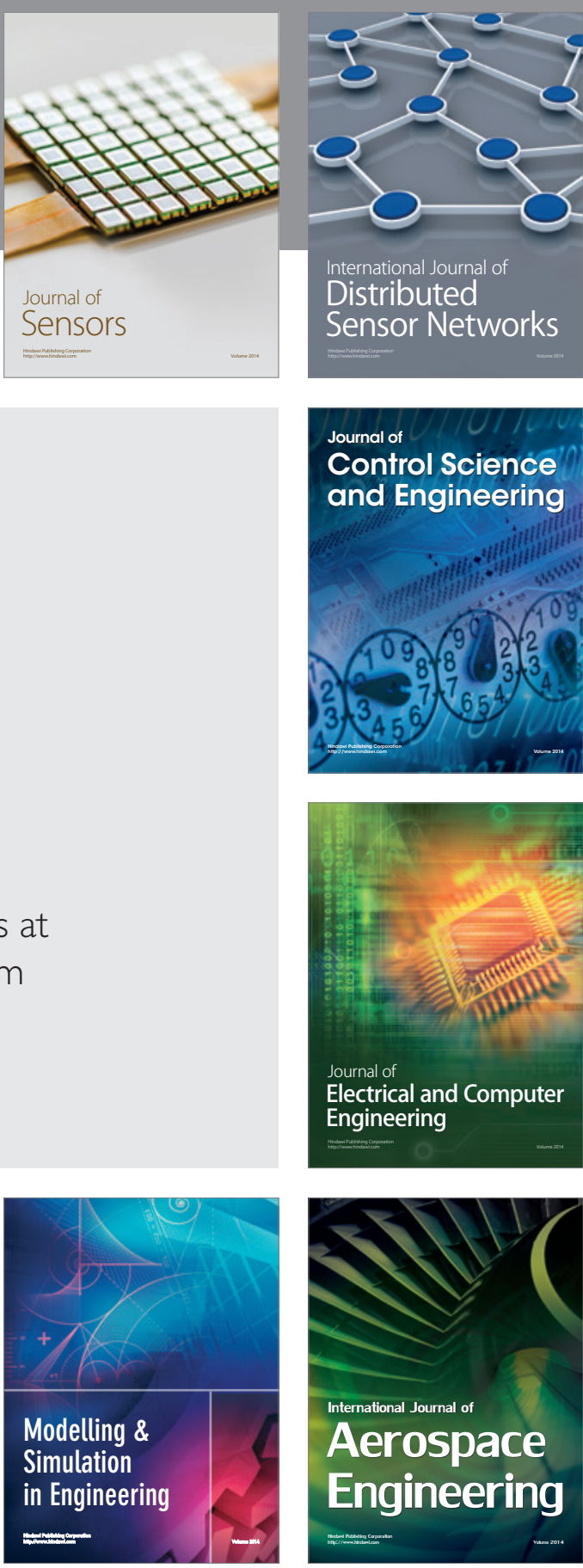

International Journal of

Distributed

Sensor Networks

Journal of

Control Science

and Engineering
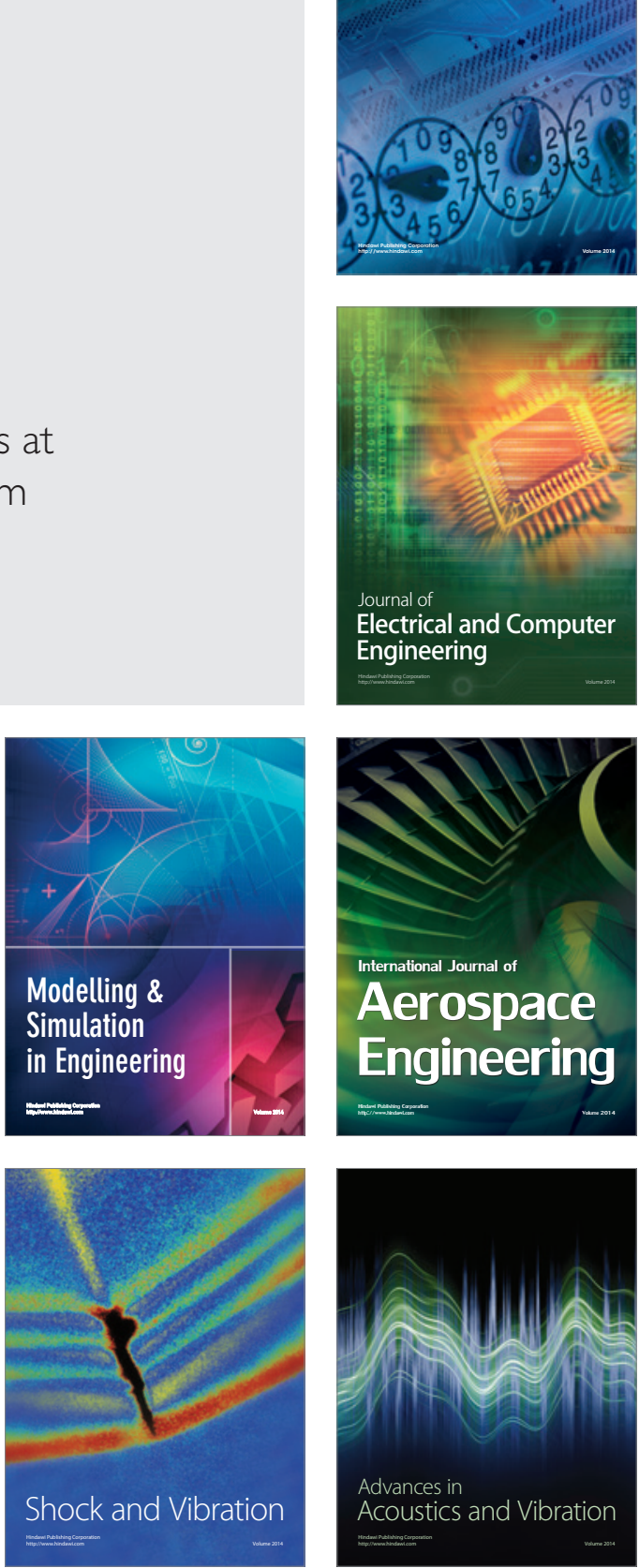